\title{
The Effects of Molecular Crowding on the Structure and Stability of G-Quadruplexes with an Abasic Site
}

\author{
Takeshi Fujimoto, ${ }^{1}$ Shu-ichi Nakano, ${ }^{1,2}$ Daisuke Miyoshi, ${ }^{1,2}$ and Naoki Sugimoto ${ }^{1,2}$ \\ ${ }^{1}$ Faculty of Frontiers of Innovative Research in Science and Technology (FIRST), Konan University, 7-1-20 Minatojima-minamimachi, \\ Chuo-ku, Kobe 650-0047, Japan \\ ${ }^{2}$ Frontier Institute for Biomolecular Engineering Research (FIBER), Konan University, 7-1-20 Minatojima-minamimachi, Chuo-ku, \\ Kobe 650-0047, Japan \\ Correspondence should be addressed to Daisuke Miyoshi, miyoshi@center.konan-u.ac.jp \\ and Naoki Sugimoto, sugimoto@konan-u.ac.jp
}

Received 20 May 2011; Revised 23 June 2011; Accepted 24 June 2011

Academic Editor: Luis A. Marky

Copyright ( 2011 Takeshi Fujimoto et al. This is an open access article distributed under the Creative Commons Attribution License, which permits unrestricted use, distribution, and reproduction in any medium, provided the original work is properly cited.

\begin{abstract}
Both cellular environmental factors and chemical modifications critically affect the properties of nucleic acids. However, the structure and stability of DNA containing abasic sites under cell-mimicking molecular crowding conditions remain unclear. Here, we investigated the molecular crowding effects on the structure and stability of the G-quadruplexes including a single abasic site. Structural analysis by circular dichroism showed that molecular crowding by PEG200 did not affect the topology of the Gquadruplex structure with or without an abasic site. Thermodynamic analysis further demonstrated that the degree of stabilization of the G-quadruplex by molecular crowding decreased with substitution of an abasic site for a single guanine. Notably, we found that the molecular crowding effects on the enthalpy change for G-quadruplex formation had a linear relationship with the abasic site effects depending on its position. These results are useful for predicting the structure and stability of G-quadruplexes with abasic sites in the cell-mimicking conditions.
\end{abstract}

\section{Introduction}

Biomolecules have evolved to function within living cells, which contain a variety of macromolecules including nucleic acids, proteins, polysaccharides, and metabolites. These molecules make the intracellular environment extremely crowded; $20-40 \%$ of the total volume is physically occupied by biomolecules [1-5]. It has been reported that molecular crowding is a critical factor determining the structure, stability and function of proteins and nucleic acids [6-18]. Because of this importance, molecular crowding effects on the structure and stability of DNA duplexes, triplexes, Gquadruplexes, and other structures have been studied [918]. These studies have demonstrated that the molecular crowding effects depend on the patterns of base-base hydrogen bonding in the nucleic acid structure. The stability of DNA duplexes and triplexes comprised of Watson-Crick base pairs decreases by molecular crowding [11-13]. In contrast, molecular crowding stabilizes DNA triplexes and quadruplexes formed by Hoogsteen base pairs $[13,14,17]$. These results suggest that the formation of noncanonical DNA structures such as triplexes and quadruplexes is induced under the molecular crowding conditions. In addition, a recent study has shown that the RNA cleavage activity of a ribozyme composed of noncanonical base-pairs and tertiary interactions was enhanced by molecular crowding [18]. These results indicate that noncanonical structures of nucleic acids can be stabilized by molecular crowding, leading to a polymorphic nature of function and structure in living cells. In fact, it is now generally accepted that noncanonical structures of nucleic acids, especially G-quadruplexes, play important roles in various biological systems [19-21].

G-quadruplexes are formed by intermolecular or intramolecular associations of guanine-rich sequences which formed four Hoogsteen base paired coplanar guanines, a structure called a G-quartet plane [22]. Bioinformatic studies 
have demonstrated that there are more than 370,000 guanine-rich sequences in the human genome [19, 23]. Importantly, these guanine-rich sequences are enriched in important genomic regions involving oncogene promoter regions, short and long minisatellite repeats, ribosomal DNAs, immunoglobulin heavy chain switch regions, and telomere regions [23-29]. As seen in telomere DNA, various biological events related to these guanine-rich sequences should be regulated by the formation of G-quadruplexes, resulting in the DNA G-quadruplex as an important target for cancer therapies [30-33]. Notably, it has been reported that the function of telomere DNA is also affected by DNA lesions [34]. The most common lesions of genomic DNA are the abasic site (apurinic/apyrimidinic (AP) site), mainly formed by hydrolysis of $N$-glycosidic bond of nucleotides [35-37]. Recently, the effects of abasic sites on the structure and stability of Gquadruplexes were reported independently by Esposito et al. and Školáková et al. [38, 39]. They each found that solution component, as well as the position of the abasic site, was important for the structure and stability of G-quadruplexes. However, the effects of abasic site on the structure and stability of G-quadruplexes under molecular crowding conditions remain unclear.

In the present study, we examined the molecular crowding effects on the structure and stability of G-quadruplexes including a single abasic site. We found that the degree of stabilization of the G-quadruplex by molecular crowding decreased by the substituting of an abasic site for a single guanine. Moreover, the molecular crowding effects on the thermodynamics of G-quadruplexes with abasic sites depended on the position of the abasic site. By comparing the molecular crowding effects and the abasic site effects on the enthalpy change during the formation of G-quadruplexes, we found that the molecular crowding effects on the enthalpy change decreased linearly as the abasic site effects increased. These results demonstrated that the effect of molecular crowding on the thermodynamics of G-quadruplexes is determined by the enthalpy change during formation, which depends on the position of the abasic site. These results are useful to predict the structure and stability of G-quadruplexes with abasic sites in cell-mimicking conditions.

\section{Materials and Methods}

2.1. Materials. DNA oligonucleotides with an abasic site were synthesized by a normal solid-phase synthetic procedure. For the abasic site, the dSpacer CE Phosphoramidite (5'-O-Dimethoxytrityl-1', $22^{\prime}$-Dideoxyribose-3' - [(2-cyanoethyl)-(N,N-diisopropyl)]-phosphoramidite) (GLEN, Sterling, VA) was used. After purification using a C18 column and a polyacrylamide gel (acrylamide: bis (acrylamide) = 19:1) and electrophoresis in $7 \mathrm{M}$ urea, the purity of the DNA oligonucleotides was confirmed to be $\sim 95 \%$. DNA oligonucleotide without abasic sites was high-performance liquid chromatography (HPLC) grade and was purchased from Hokkaido System Science (Sapporo, Japan). Singlestrand concentrations of DNA oligonucleotides were determined by measuring the absorbance at $260 \mathrm{~nm}$ at a high temperature using a Shimadzu 1700 spectrophotometer (Kyoto, Japan) connected to a thermo programmer. Singlestrand extinction coefficients were calculated from mononucleotide and dinucleotide data using the nearest-neighbour approximation $[40,41]$.

2.2. Structural Analysis. Circular dichroism (CD) spectra utilizing a JASCO J-820 spectropolarimeter (Hachioji, Japan) were measured at $4^{\circ} \mathrm{C}$ in a $0.1-\mathrm{cm}$-path-length curette for $20 \mu \mathrm{M}$ total strand concentration of DNA in a buffer of $100 \mathrm{mM} \mathrm{NaCl}, 50 \mathrm{mM}$ Tris- $\mathrm{HCl}(\mathrm{pH} 7.0)$, and $1 \mathrm{mM}$ $\mathrm{Na}_{2}$ EDTA at $0 \mathrm{wt} \%\left(0 \mathrm{~mol} \mathrm{~L}^{-1}\right)$ and $40 \mathrm{wt} \%\left(2 \mathrm{~mol} \mathrm{~L}^{-1}\right)$ PEG200 (poly(ethylene glycol) with an average molecular weight of 200). The CD spectra were obtained by taking the average of at least three scans made from 200 to $350 \mathrm{~nm}$. The temperature of the cell holder was regulated by a JASCO PTC-348 temperature controller, and the cuvette-holding chamber was flushed with a constant stream of dry $\mathrm{N}_{2}$ gas to avoid condensation of water on the cuvette exterior. Before the measurement, the sample was heated to $80^{\circ} \mathrm{C}$, gently cooled at a rate of $2^{\circ} \mathrm{C} \mathrm{min}{ }^{-1}$, and incubated $1 \mathrm{~h}$ at $4^{\circ} \mathrm{C}$.

2.3. Thermodynamic Analysis. The UV absorbance of the DNA oligonucleotides with were measured by a Shimadzu 1700 spectrophotometer (Kyoto, Japan) equipped with a temperature controller. The UV melting curves of G-quadruplexes were measured at $295 \mathrm{~nm}$ where G-quadruplexes showed hypochromic transition [42]. All experiments were carried out in a buffer of $100 \mathrm{mM} \mathrm{NaCl}, 50 \mathrm{mM}$ Tris- $\mathrm{HCl}(\mathrm{pH}$ 7.0), and $1 \mathrm{mM} \mathrm{Na} \mathrm{mDDT}_{2}$ at $0 \mathrm{wt} \%\left(0 \mathrm{~mol} \mathrm{~L}^{-1}\right)$ and $40 \mathrm{wt} \%$ $\left(2 \mathrm{~mol} \mathrm{~L}^{-1}\right) \mathrm{PEG} 200$. The heating rate was $0.5^{\circ} \mathrm{C} \mathrm{min}^{-1}$. The thermodynamic parameters $\left(\Delta H^{\circ}, \Delta S^{\circ}, \Delta G_{37}^{\circ}\right)$ were calculated from the fit of the melting curves (with at least four different concentrations of DNA) to a theoretical equation for a two-state model of intramolecular association as described previously [41]. The thermodynamic parameters are the average values obtained from the curve-fitting analysis. Before the measurement, the sample was heated to $80^{\circ} \mathrm{C}$, gently cooled at a rate of $2^{\circ} \mathrm{C} \mathrm{min}-1$, and incubated $1 \mathrm{~h}$ at $0^{\circ} \mathrm{C}$.

2.4. Water Activity Measurement. The water activity was determined by the osmotic stressing method via vapor phase osmometry using a model 5520XR pressure osmometer (Wescor, Utah, USA.). In order to calculate the water activity with various concentrations of PEG200, we assumed that PEG200 did not interact directory with DNA $[11,12]$.

\section{Results and Discussion}

3.1. Sequence Design. We used the human telomere DNA sequence $\left(d A\left(G_{3} T_{2} A\right)_{3} G_{3}\right)$ because previous studies have reported that this sequence folds into an intramolecular antiparallel G-quadruplex in the presence of $\mathrm{Na}^{+}$(Figure 1(a)) [43]. In order to understand the effects of molecular crowding on the structure and stability of G-quadruplexes with abasic sites, we designed and synthesized human telomere DNA sequences with a single abasic site instead of a guanine base. The DNA sequences and their abbreviations used in 


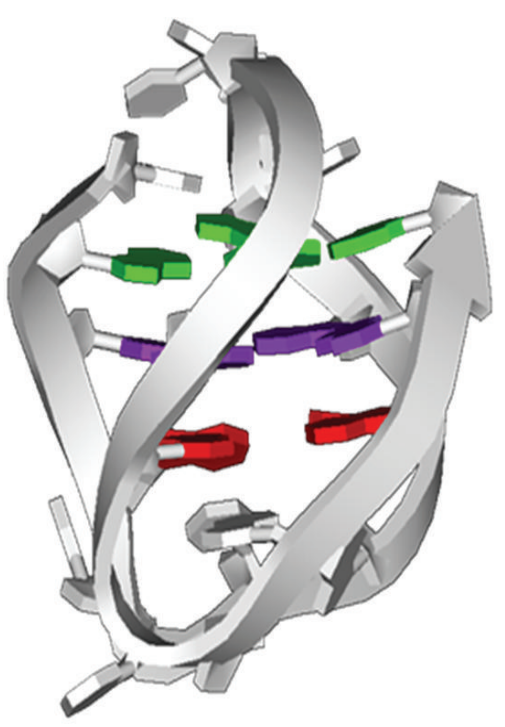

(a)

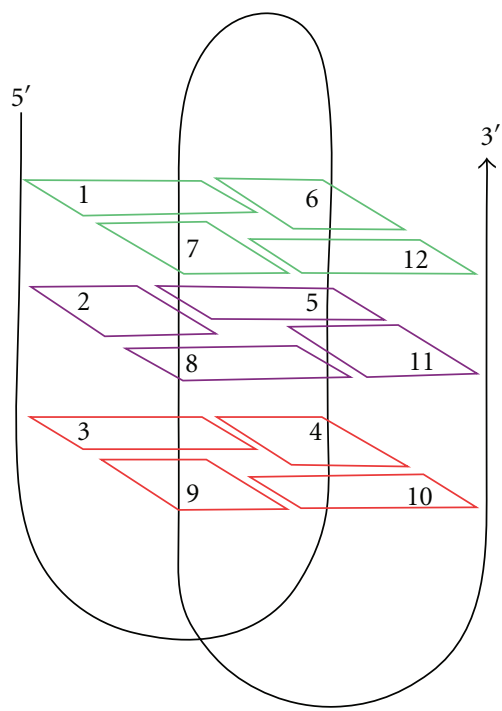

(b)

FIGURE 1: (a) Structure of human telomere $\left(5^{\prime}-\mathrm{A}\left(\mathrm{G}_{3} \mathrm{~T}_{2} \mathrm{~A}\right)_{3} \mathrm{G}_{3}-3^{\prime}\right)$ G-quadruplex in the presence of Na ${ }^{+}$(PDB ID: 143D). (b) Schematic illustration of G-quadruplex AP-0 with a top G-quartet plane (green), middle G-quartet plane (purple), and bottom G-quartet plane (red). The numbers indicate the position of abasic sites (AP- $X$ ( $X$ indicates 1 to 11$)$ ).

TABLE 1: DNA sequences used in this study.

\begin{tabular}{ll}
\hline Abbreviation & \multicolumn{1}{c}{ Sequence } \\
\hline AP-0 & $5^{\prime}$-AGGGTTAGGGTTAGGGTTAGGG-3' \\
AP-1 & 5'-AøGGTTAGGGTTAGGGTTAGGG-3' \\
AP-2 & 5'-AGøGTTAGGGTTAGGGTTAGGG-3' \\
AP-3 & $5^{\prime}$-AGGøTTAGGGTTAGGGTTAGGG-3' \\
AP-4 & $5^{\prime}$-AGGGTTAøGGTTAGGGTTAGGG-3' \\
AP-5 & $5^{\prime}$-AGGGTTAGøGTTAGGGTTAGGG-3' \\
AP-6 & $5^{\prime}$-AGGGTTAGGøTTAGGGTTAGGG-3' \\
AP-7 & $5^{\prime}$-AGGGTTAGGGTTAøGGTTAGGG-3' \\
AP-8 & $5^{\prime}$-AGGGTTAGGGTTAGøGTTAGGG-3' \\
AP-9 & $5^{\prime}$-AGGGTTAGGGTTAGGøTTAGGG-3' \\
AP-10 & $5^{\prime}$-AGGGTTAGGGTTAGGGTTAøGG-3' \\
AP-11 & $5^{\prime}$-AGGGTTAGGGTTAGGGTTAGøG-3' \\
\hline
\end{tabular}

$\emptyset$ indicates the abasic site.

this study are listed in Table 1. Figure 1(b) shows a schematic structure of the antiparallel G-quadruplex of AP-0 in the presence of $\mathrm{Na}^{+}$[43]. When the first guanine is at the top of the G-quartet plane, AP-1, AP-6, and AP-7 contain the abasic site in the top G-quartet plane. AP-2, AP-5, AP-8, and AP-11 contain the abasic site in the middle G-quartet plane. AP-3, AP-4, AP-9, and AP-10 contain the abasic site in the bottom G-quartet plane. By comparing these sequences, it is possible to systematically investigate the molecular crowding effects on the G-quadruplex containing an abasic site at different positions.

3.2. Molecular Crowding Effects on the Structures of DNA Sequences with or without an Abasic Site. We initially studied the folding topologies of DNA sequences by $\mathrm{CD}$ spectroscopy. Figure 2(a) shows CD spectra of AP-0, AP-1, AP2 , and AP-3 in $100 \mathrm{mM} \mathrm{NaCl}$ buffer at $0 \mathrm{wt} \%$ PEG200 as a dilute condition. The CD spectrum of AP-0 showed positive and negative peaks around $295 \mathrm{~nm}$ and $260 \mathrm{~nm}$, respectively. This CD spectrum indicates the formation of an antiparallel G-quadruplex [43], which is consistent with a previous NMR study showing that AP-0 forms an intramolecular antiparallel G-quadruplex in the presence of $\mathrm{Na}^{+}$(Figure 1(a)) [39]. The CD spectra of AP-1, AP-2, and AP-3 also showed positive and negative peaks around $295 \mathrm{~nm}$ and $260 \mathrm{~nm}$, respectively, also showing the formation of an antiparallel Gquadruplex. Typical CD spectra for antiparallel G-quadruplexes were further observed for AP-0, AP-1, AP-2, and AP-3 under molecular crowding conditions with $40 \mathrm{wt} \%$ PEG200 (Figure 2(b)). We chose $40 \mathrm{wt} \%$ PEG200 as the molecular crowding condition because, inside living cells, 20-40 wt $\%$ total volume is physically occupied by biomolecules [15]. In addition, higher concentrations of PEG200 than $40 \mathrm{wt} \%$ sometime induce condensation of DNA. In addition, CD spectra of all DNA sequences at $0 \mathrm{wt} \%$ and $40 \mathrm{wt} \%$ PEG200 were almost identical with that of AP-0 (see Figure $\mathrm{S} 1$ in the Supplementary Material (available online at doi:10.4061/2011/857149) for CD spectra of DNA sequences from AP-4 to AP-11), showing that all DNA sequences form antiparallel G-quadruplexes under both dilute and molecular crowding conditions. These results demonstrated that molecular crowding did not alter the folding topology of G-quadruplexes. On the other hand, the CD intensities of the DNA sequences were different from each other, suggesting that loss of the stacking interaction in the antiparallel G-quadruplexes depends on the position of the abasic site. 


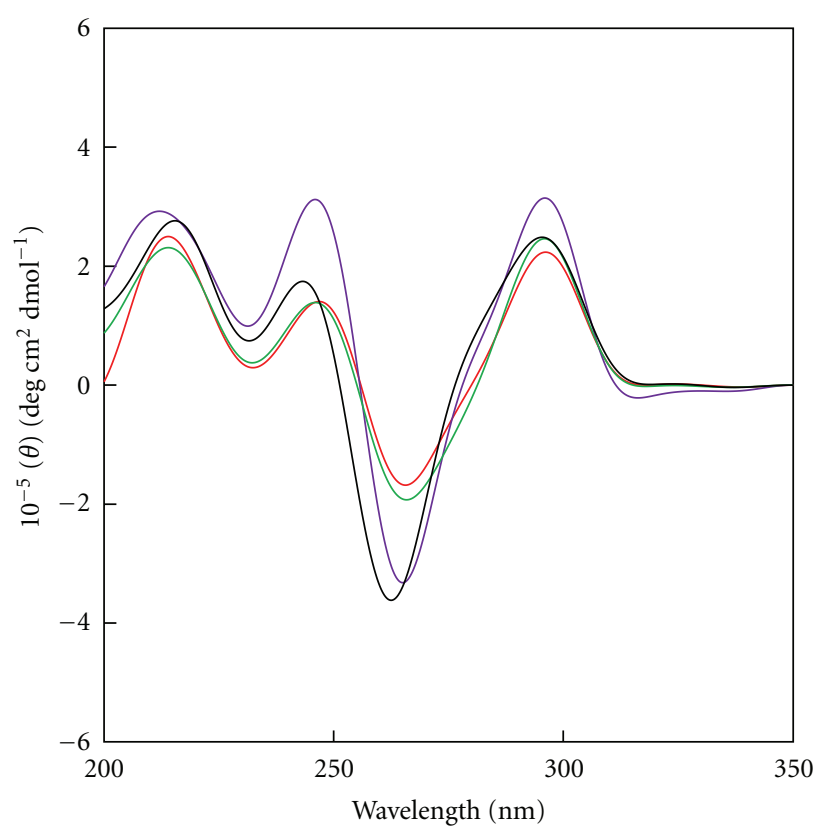

(a)

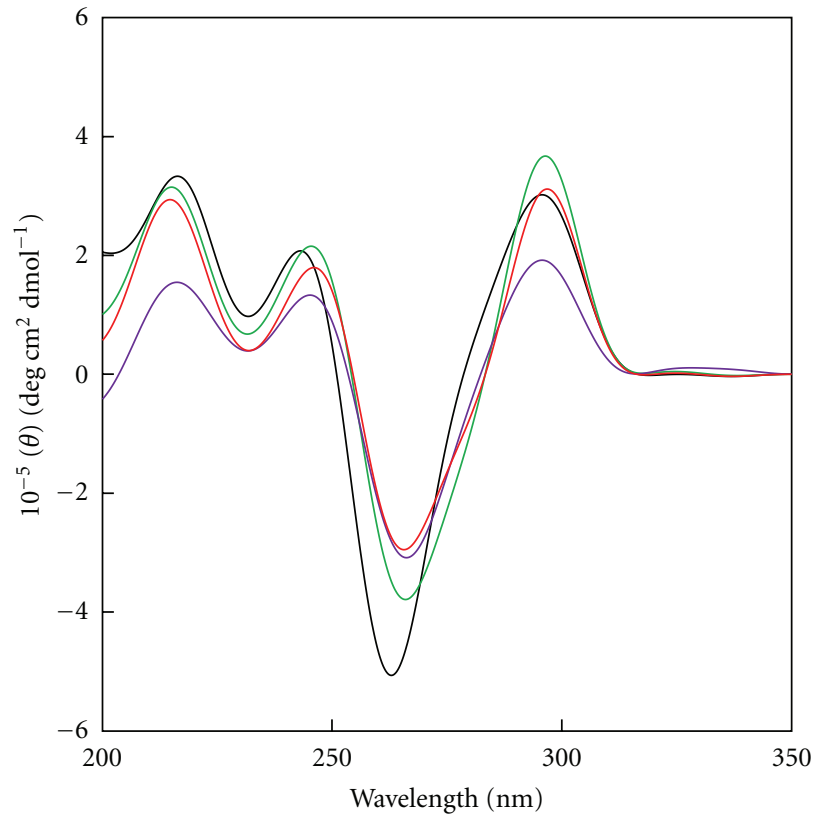

(b)

Figure 2: CD spectra for $20 \mu \mathrm{M}$ AP-0 (black), AP-1 (green), AP-2 (purple), and AP-3 (red) in a buffer of $100 \mathrm{mM} \mathrm{NaCl,} 50 \mathrm{mM}$ Tris-HCl ( $\mathrm{pH} 7.0)$, and $1 \mathrm{mM} \mathrm{Na}_{2}$ EDTA at $0 \mathrm{wt} \%\left(0 \mathrm{~mol} \mathrm{~L}^{-1}\right)(\mathrm{a})$ and $40 \mathrm{wt} \%\left(2 \mathrm{~mol} \mathrm{~L}^{-1}\right)$ PEG200 (b) at $4^{\circ} \mathrm{C}$.

3.3. Molecular Crowding Effects on the Thermodynamics of GQuadruplexes with or without an Abasic Site. Since all sequences folded into antiparallel G-quadruplexes under dilute and molecular crowding conditions, we further attempted to evaluate the effects of molecular crowding on the thermodynamics of G-quadruplexes with or without an abasic site. Figure 3(a) shows normalized UV melting curves at $295 \mathrm{~nm}$ of AP-0 at $0 \mathrm{wt} \%$ and $40 \mathrm{wt} \%$ PEG200. Hypochromic transitions were observed, indicating that these melting behaviours corresponded to the dissociation of G-quadruplexes [42]. In addition, hysteresis was not observed between the melting and annealing curves for any sequence (data not shown), indicating a two-state transition of the G-quadruplexes. The values of melting temperature $\left(T_{m}\right)$ of AP-0 at $0 \mathrm{wt} \%$ and $40 \mathrm{wt} \%$ PEG200 were estimated to be $58.1^{\circ} \mathrm{C}$ and $66.9^{\circ} \mathrm{C}$, respectively (Table 2 ). The $T_{m}$ values of AP-1, AP-2, and AP3 at $0 \mathrm{wt} \%$ were $52.2^{\circ} \mathrm{C}, 44.2^{\circ} \mathrm{C}$, and $50.0^{\circ} \mathrm{C}$, respectively. At $40 \mathrm{wt} \%$ PEG200, the $T_{m}$ values of the DNA sequences were $61.9^{\circ} \mathrm{C}, 53.2^{\circ} \mathrm{C}$, and $57.2^{\circ} \mathrm{C}$, respectively. In addition, the $T_{m}$ values of DNA sequences from AP-4 to AP-11 at $0 \mathrm{wt} \%$ and $40 \mathrm{wt} \%$ PEG200 are listed in Table 2. All DNA sequences showed higher $T_{m}$ at $40 \mathrm{wt} \%$ PEG200 than at $0 \mathrm{wt} \%$ PEG200. These results indicate that molecular crowding stabilizes Gquadruplexes with or without an abasic site.

The values of free energy changes at $37^{\circ} \mathrm{C}\left(\Delta G_{37}^{\circ}\right)$ for G-quadruplex formations at $0 \mathrm{wt} \%$ and $40 \mathrm{wt} \%$ PEG200 were further evaluated and are listed in Table 2. Moreover, we evaluated thermodynamic stability of G-quadruplexes of the natural AP-0 and modified AP-1 at 10, 20, and $30 \mathrm{wt} \%$ PEG200 as well as 0 and $40 \mathrm{wt} \%$ PEG200 to investigate a relationship between the stability of the G-quadruplex $\left(\ln K_{\mathrm{obs}}\right)$ and water activity $\left(\ln a_{\mathrm{w}}\right)$ at $37^{\circ} \mathrm{C}($ Figure 4$)$.
The plot showed that the stability of the G-quadruplex $\left(\ln K_{\text {obs }}\right)$ decreased linearly with the increase in $\ln a_{\mathrm{w}}$. Thus, the slope is approximately equal to the numbers of water molecules released upon the formation of the structure [12]. The numbers of water molecules released upon the Gquadruplex formation of AP-0 and AP-1 were estimated to be 74.7 and 56.8, respectively. These results are consistent with the previous reports for the numbers of water molecules through the formation of G-quadruplexes $[12,15]$. Noteworthy, this linear relationship between $\ln K_{\mathrm{obs}}$ and $\ln a_{\mathrm{w}}$ indicates that cosolute and cation bindings to G-quadruplex are insignificant. We previously used various neutral cosolutes to induce molecular crowding conditions and to study direct interactions between cosolutes and DNA strand [11, 12]. We found that a cosolute with fewer hydroxyl groups in the vicinal position causes more water molecules to be released during formation of the G-quadruplex. From these results, it is possible to consider that the cosolutes affect the thermodynamics of G-quadruplex by regulating the hydration of the DNA molecule. On the other hand, it was reported that a direct interaction between PEG and DNA strand is thermodynamically unfavorable [45]. Thus, it appears that indirect interactions with cosolutes containing fewer hydroxyl groups, such as PEG, affect the hydration of the DNA structures. These results suggest that the stabilization effect of molecular crowding on G-quadruplex structures with or without an abasic site is due to the hydration change induced by the addition of PEG200.

Based on $\Delta G_{37}^{\circ}$, we further estimated the effects of molecular crowding as follows: $\Delta \Delta G_{37(\mathrm{MC})}^{\circ}=\left\{\Delta G_{37(40 \mathrm{wt} \% \text { PEG200) }}^{\circ}\right\}-$ $\left\{\Delta G_{37(0 \mathrm{wt} \% \text { PEG } 200)}^{\circ}\right\}$. The value of $\Delta \Delta G_{37(\mathrm{MC})}^{\circ}$ for AP-0 was $-2.3 \mathrm{kcal} \mathrm{mol}^{-1}$. This negative value of $\Delta \Delta G_{37(\mathrm{MC})}^{\circ}$ 


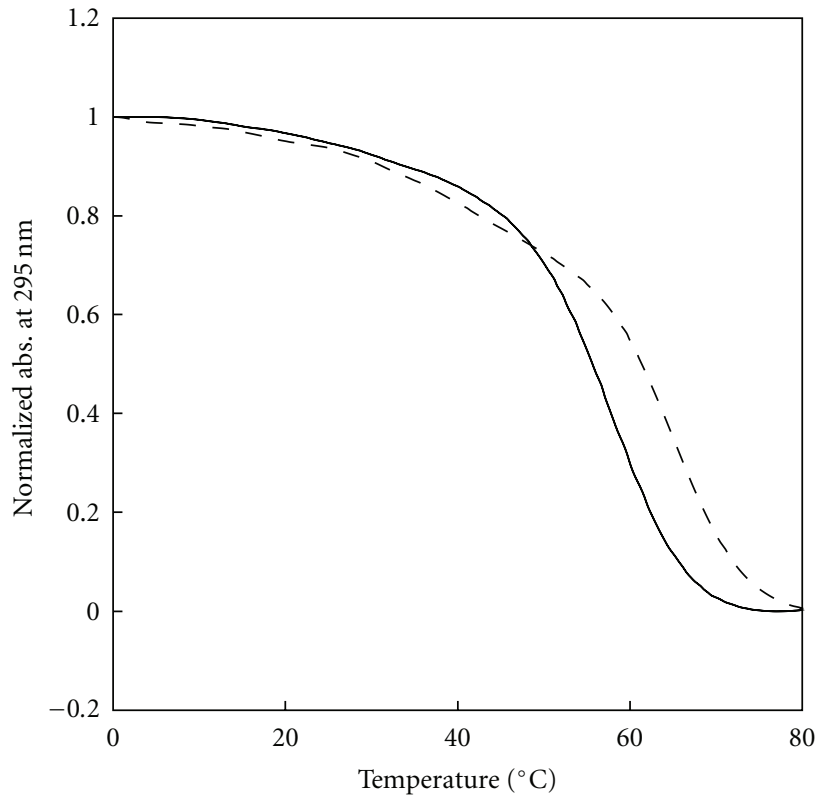

(a)

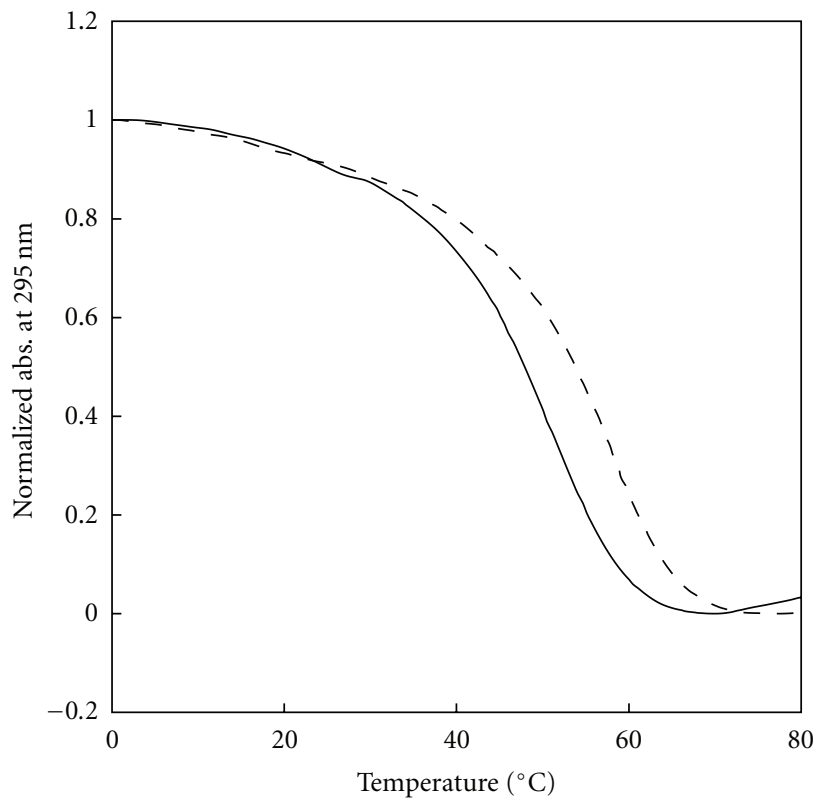

(c)

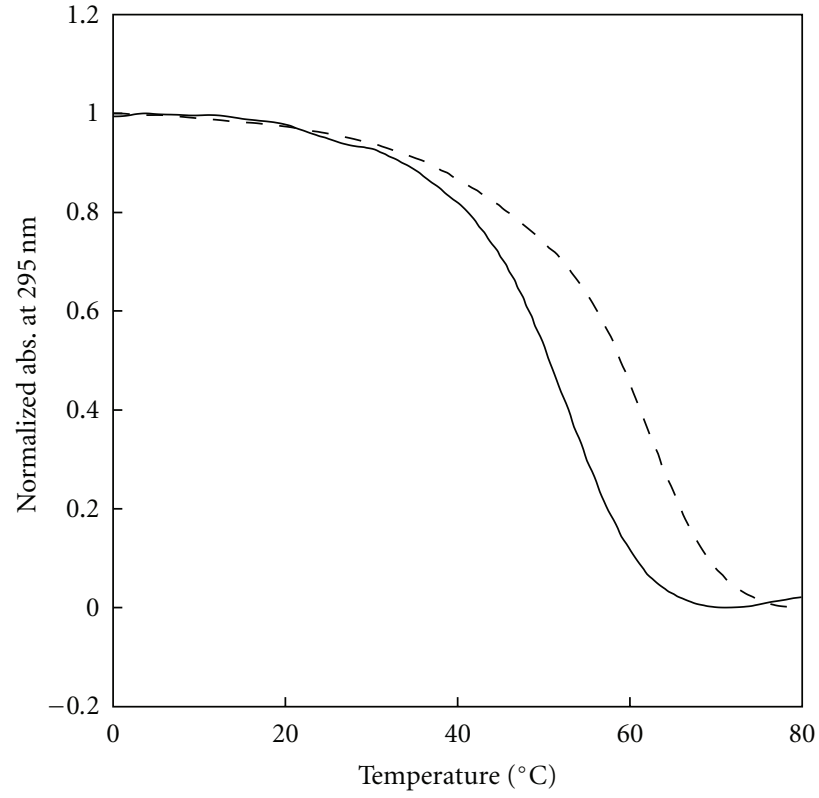

(b)

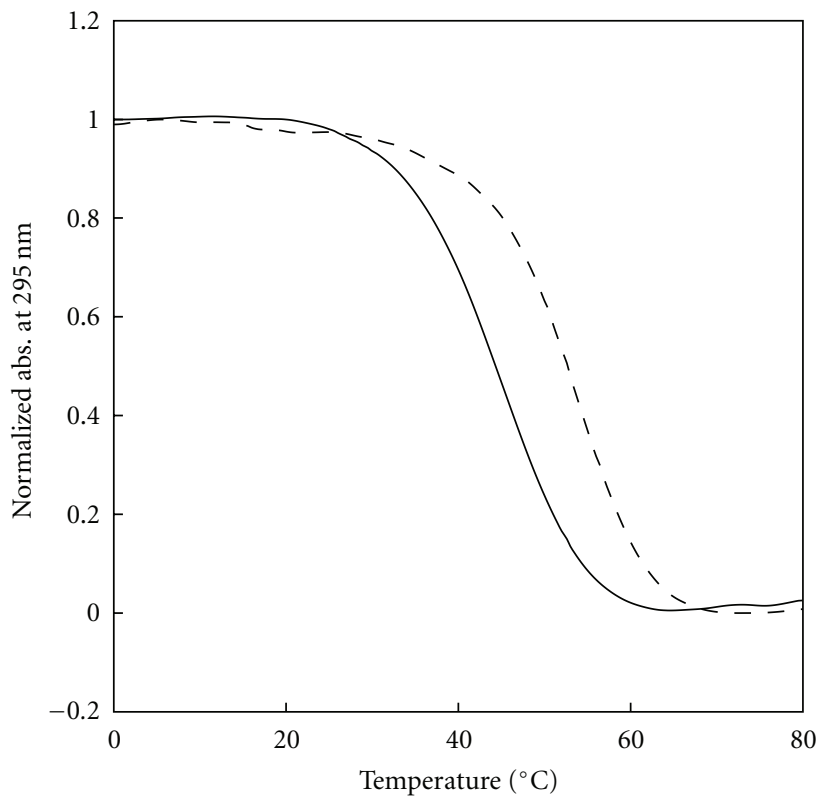

(d)

Figure 3: Normalized UV melting curves for $20 \mu \mathrm{M} \mathrm{AP-0} \mathrm{(a),} \mathrm{AP-1} \mathrm{(b),} \mathrm{AP-2} \mathrm{(c),} \mathrm{and} \mathrm{AP-3} \mathrm{(d)} \mathrm{in} \mathrm{a} \mathrm{buffer} \mathrm{of} 100 \mathrm{mM} \mathrm{NaCl,} 50 \mathrm{mM}$ Tris-HCl ( $\mathrm{pH} 7.0)$, and $1 \mathrm{mM} \mathrm{Na}_{2}$ EDTA at $0 \mathrm{wt} \%\left(0 \mathrm{~mol} \mathrm{~L}^{-1}\right)$ (solid line) and $40 \mathrm{wt} \%\left(2 \mathrm{~mol} \mathrm{~L}^{-1}\right)$ (dashed line) PEG200.

quantitatively shows that molecular crowding stabilizes natural G-quadruplexes, which is consistent with previous studies for molecular crowding effects on the antiparallel Gquadruplex stability [46]. By comparing $\Delta \Delta G_{37(\mathrm{MC})}^{\circ}$ for AP-0 $\left(-2.3 \mathrm{kcal} \mathrm{mol}^{-1}\right)$ with those of AP-1 $\sim$ AP-11 $\left(-1.1 \mathrm{kcal} \mathrm{mol}^{-1} \sim-1.9 \mathrm{kcal} \mathrm{mol}^{-1}\right)$, we found that the degree of stabilization by molecular crowding was reduced by the introduction of an abasic site. Moreover, we found that the stabilizing effect of molecular crowding was the largest for G-quadruplexes with an abasic site in the middle G-quartet plane (see Figure $1(\mathrm{~b})$ ). The average value of $\Delta \Delta G_{37(\mathrm{MC})}^{\circ}$ for AP-2 $\left(-1.5 \mathrm{kcal} \mathrm{mol}^{-1}\right)$, AP$5\left(-1.7 \mathrm{kcal} \mathrm{mol}^{-1}\right), \mathrm{AP}-8\left(-1.8 \mathrm{kcal} \mathrm{mol}^{-1}\right)$, and AP-11 $\left(-1.9 \mathrm{kcal} \mathrm{mol}^{-1}\right)$ was estimated to be $-1.7 \mathrm{kcal} \mathrm{mol}^{-1}$, which is greater in magnitude than that of AP-1, AP-6, or AP-7 possessing abasic sites in the top G-quartet plane $\left(-1.5 \mathrm{kcal} \mathrm{mol}^{-1}\right)$, and larger in magnitude than that of AP-3, AP-4, AP-9, and AP-10 possessing an abasic site in the bottom G-quartet plane $\left(-1.3 \mathrm{kcal} \mathrm{mol}^{-1}\right)$. These results indicated that the abasic site position critically affected 
TABLE 2: Thermodynamic parameters of AP series for the formation of G-quadruplex ${ }^{\mathrm{a}}$.

\begin{tabular}{|c|c|c|c|c|c|c|c|}
\hline & $\begin{array}{c}\text { PEG200 } \\
(w t \%)\end{array}$ & $\begin{array}{l}T_{m}{ }^{b} \\
\left({ }^{\circ} \mathrm{C}\right)\end{array}$ & $\begin{array}{c}\Delta H^{\circ} \\
\left(\mathrm{kcal} \mathrm{mol}^{-1}\right)\end{array}$ & $\begin{array}{c}T \Delta S^{\circ} \\
\left(\mathrm{kcal} \mathrm{mol}^{-1}\right)\end{array}$ & $\begin{array}{c}\Delta G_{37}^{\circ} \\
\left(\mathrm{kcal} \mathrm{mol}^{-1}\right)\end{array}$ & $\begin{array}{l}\Delta \Delta G_{37(\mathrm{MC})}^{\circ} \\
\left(\mathrm{kcal} \mathrm{mol}^{-1}\right)\end{array}$ & $\begin{array}{l}\Delta \Delta G_{37(\mathrm{AP}-X)}^{\circ}{ }^{\mathrm{d}} \\
\left(\mathrm{kcal} \mathrm{mol}^{-1}\right)\end{array}$ \\
\hline \multirow{2}{*}{ AP-0 } & 0 & 58.1 & $-47.9 \pm 0.3$ & $-44.8 \pm 0.3$ & $-3.1 \pm 0.4$ & $-2.3 \pm 1.0$ & - \\
\hline & 40 & 66.9 & $-62.1 \pm 1.0$ & $-56.6 \pm 0.8$ & $-5.5 \pm 1.0$ & - & - \\
\hline \multirow{2}{*}{ AP-1 } & 0 & 52.2 & $-41.3 \pm 0.4$ & $-39.4 \pm 0.5$ & $-1.9 \pm 0.6$ & $-1.6 \pm 1.0$ & $1.2 \pm 0.7$ \\
\hline & 40 & 61.9 & $-46.5 \pm 0.6$ & $-43.0 \pm 0.6$ & $-3.5 \pm 0.8$ & - & $1.9 \pm 1.2$ \\
\hline \multirow{2}{*}{ AP-2 } & 0 & 44.2 & $-40.8 \pm 0.5$ & $-39.9 \pm 0.5$ & $-0.9 \pm 0.3$ & $-1.5 \pm 1.0$ & $2.2 \pm 0.5$ \\
\hline & 40 & 53.2 & $-48.2 \pm 0.8$ & $-45.8 \pm 0.7$ & $-2.4 \pm 0.8$ & - & $3.0 \pm 1.3$ \\
\hline \multirow{2}{*}{ AP-3 } & 0 & 50.0 & $-42.1 \pm 0.6$ & $-40.4 \pm 0.6$ & $-1.7 \pm 0.7$ & $-1.2 \pm 1.5$ & $1.4 \pm 0.8$ \\
\hline & 40 & 57.2 & $-47.9 \pm 1.0$ & $-45.0 \pm 0.9$ & $-2.9 \pm 1.4$ & - & $2.5 \pm 1.7$ \\
\hline \multirow{2}{*}{ AP-4 } & 0 & 39.1 & $-38.6 \pm 0.3$ & $-38.3 \pm 0.3$ & $-0.3 \pm 0.3$ & $-1.1 \pm 0.3$ & $2.8 \pm 0.5$ \\
\hline & 40 & 46.2 & $-47.9 \pm 0.4$ & $-46.3 \pm 0.3$ & $-1.4 \pm 0.3$ & - & $4.0 \pm 1.0$ \\
\hline \multirow{2}{*}{ AP-5 } & 0 & 30.9 & $-32.6 \pm 0.3$ & $-33.3 \pm 0.3$ & $0.7 \pm 0.3$ & $-1.7 \pm 0.6$ & $3.8 \pm 0.5$ \\
\hline & 40 & 43.8 & $-46.1 \pm 0.4$ & $-45.1 \pm 0.4$ & $-1.0 \pm 0.5$ & - & $4.4 \pm 1.1$ \\
\hline \multirow{2}{*}{ AP-6 } & 0 & 47.0 & $-40.7 \pm 0.4$ & $-39.4 \pm 0.4$ & $-1.3 \pm 0.6$ & $-1.5 \pm 0.9$ & $1.8 \pm 0.7$ \\
\hline & 40 & 56.1 & $-48.1 \pm 0.6$ & $-45.3 \pm 0.6$ & $-2.8 \pm 0.7$ & - & $2.6 \pm 1.2$ \\
\hline \multirow{2}{*}{ AP-7 } & 0 & 43.5 & $-45.1 \pm 0.4$ & $-44.2 \pm 0.4$ & $-0.9 \pm 0.5$ & $-1.3 \pm 0.9$ & $2.2 \pm 0.6$ \\
\hline & 40 & 51.3 & $-48.4 \pm 0.4$ & $-46.1 \pm 0.4$ & $-2.2 \pm 0.5$ & - & $3.2 \pm 1.1$ \\
\hline \multirow{2}{*}{ AP-8 } & 0 & 33.5 & $-31.3 \pm 0.3$ & $-31.7 \pm 0.3$ & $0.4 \pm 0.3$ & $-1.8 \pm 0.6$ & $3.5 \pm 0.5$ \\
\hline & 40 & 46.7 & $-46.4 \pm 0.3$ & $-45.0 \pm 0.3$ & $-1.4 \pm 0.3$ & - & $4.0 \pm 1.0$ \\
\hline \multirow{2}{*}{ AP-9 } & 0 & 41.1 & $-35.2 \pm 0.2$ & $-33.3 \pm 0.3$ & $-0.5 \pm 0.3$ & $-1.4 \pm 0.4$ & $2.6 \pm 0.5$ \\
\hline & 40 & 49.5 & $-47.5 \pm 0.4$ & $-45.6 \pm 0.3$ & $-1.9 \pm 0.3$ & - & $3.5 \pm 1.0$ \\
\hline \multirow{2}{*}{ AP-10 } & 0 & 38.8 & $-37.5 \pm 0.4$ & $-37.3 \pm 0.4$ & $-0.2 \pm 0.5$ & $-1.3 \pm 0.6$ & $2.9 \pm 0.6$ \\
\hline & 40 & 48.0 & $-44.8 \pm 0.3$ & $-43.3 \pm 0.3$ & $-1.5 \pm 0.4$ & - & $3.9 \pm 1.1$ \\
\hline \multirow{2}{*}{ AP-11 } & 0 & 36.4 & $-33.3 \pm 0.7$ & $-33.5 \pm 0.7$ & $0.2 \pm 0.7$ & $-1.9 \pm 1.1$ & $3.3 \pm 0.9$ \\
\hline & 40 & 48.1 & $-42.8 \pm 0.7$ & $-41.1 \pm 0.6$ & $-1.7 \pm 0.7$ & - & $3.7 \pm 1.2$ \\
\hline
\end{tabular}

${ }^{a}$ The error values were calculate as shown in [44].

${ }^{\mathrm{b}} T_{m}$ is the melting temperature at $20 \mu \mathrm{M}$ total strand concentration.

${ }^{\mathrm{c}} \Delta \Delta G_{37(\mathrm{MC})}^{\circ}=\Delta G_{37(40 \mathrm{wt} \% \mathrm{PEG} 200)}^{\circ}-\Delta G_{37(0 \mathrm{wt} \% \mathrm{PEG} 200)}^{\circ}$.

${ }^{\mathrm{d}} \Delta \Delta G_{37 \text { (AP- } X)}^{\circ}=\Delta G_{37 \text { (AP-X) }}^{\circ}-\Delta G_{37 \text { (AP- } 0)}^{\circ}(X$ indicates the numbers from 1 to 11$)$.

the molecular crowding effect on the thermodynamics of Gquadruplex.

When the PEG200 concentration increased from 0 to $40 \mathrm{wt} \%$, the enthalpy change $\left(\Delta H^{\circ}\right)$ of AP-0 for G-quadruplex formation was more favorable, decreasing from -47.9 to $-62.1 \mathrm{kcal} \mathrm{mol}^{-1}$, and the entropy change at $37^{\circ} \mathrm{C}\left(T \Delta S^{\circ}\right)$ was more favorable, decreasing from -44.8 to $-56.8 \mathrm{kcal}$ $\mathrm{mol}^{-1}$. Similarly, $\Delta H^{\circ}$ and $T \Delta S^{\circ}$ values for AP-1, AP-2, and AP-3 for G-quadruplex formation decreased with increasing PEG concentration from $0 \mathrm{wt} \%$ to $40 \mathrm{wt} \%$. These changes demonstrate that the promotion of G-quadruplex formation by molecular crowding is due to a favourable enthalpic contribution that exceeds the unfavourable entropic contribution. The enthalpic stabilization of G-quadruplexes by molecular crowding agrees with previous reports showing a stabilization effect of molecular crowding on a thrombinbinding aptamer forming an antiparallel G-quadruplex [12, 15]. Moreover, these results demonstrate that the enthalpic contribution of molecular crowding to the thermodynamics of G-quadruplexes depends on the position of the abasic site.
3.4. The Effects of the Abasic Site on the Thermodynamics of DNA G-Quadruplexes. In order to understand how the abasic site regulates the molecular crowding effects on the thermodynamics of G-quadruplexes, we compared the thermodynamic stability of nonmodified (AP-0) and modified G-quadruplexes (AP-1 AP-11) under dilute conditions. The thermodynamic stability of AP-0 was higher than that of AP-1 AP-11 (Table 2). These parameters are consistent with the destabilization of G-quadruplexes by abasic sites as was reported in a previous study [39]. The abasic site effects were quantitatively evaluated as follows: $\Delta \Delta G_{37 \text { (AP- } X)}^{\circ}=\Delta G_{37 \text { (AP- } X)}^{\circ}-\Delta G_{37 \text { (AP- } 0)}^{\circ}(X$ indicates numbers from 1 to 11 ). For example, $\Delta \Delta G_{37 \text { (AP-1) }}^{\circ}$ at $0 \mathrm{wt} \%$ PEG200 was $1.2 \mathrm{kcal} \mathrm{mol}^{-1}$. Moreover, we found that the value of $\Delta \Delta G_{37 \text { (AP-X) }}^{\circ}$ was the largest for G-quadruplexes with abasic sites in the middle G-quartet plane (AP-2, AP$5, \mathrm{AP}-8$, and AP-11). The average value was estimated to be $3.2 \mathrm{kcal} \mathrm{mol}^{-1}$, which was larger than that of AP-1, AP6, and AP-7 possessing abasic sites in the top G-quartet plane $\left(1.7 \mathrm{kcal} \mathrm{mol}^{-1}\right)$, and larger than that of AP-3, AP-4, 


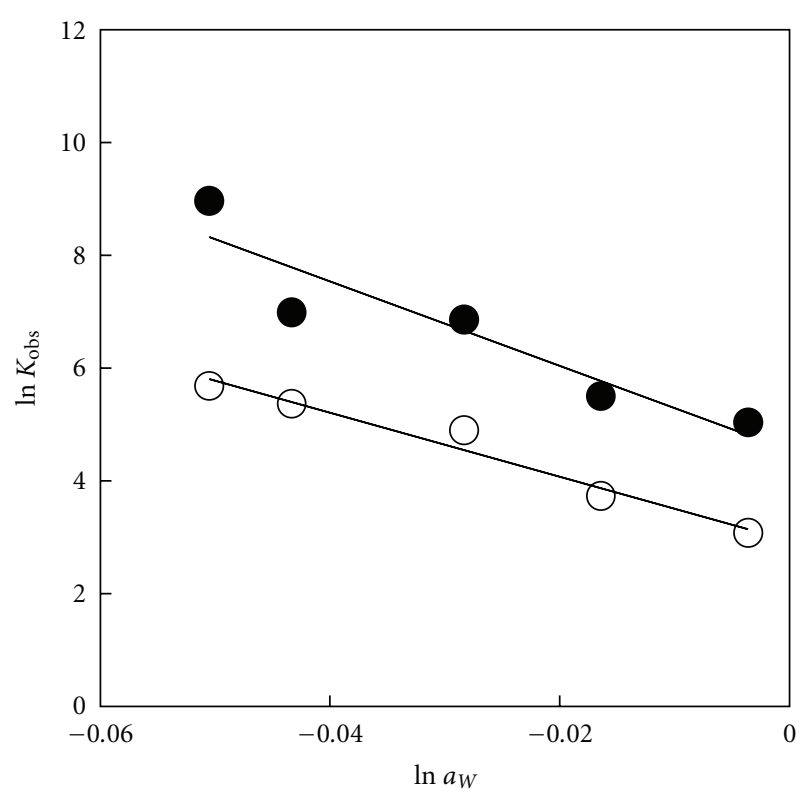

Figure 4: Plots of $\ln K_{\text {obs }}$ versus $\ln a_{w}$ for AP-0 (closed circle) and AP-1 (open circle) for the formation of the G-quadruplex in a buffer of $100 \mathrm{mM} \mathrm{NaCl}, 50 \mathrm{mM}$ Tris- $\mathrm{HCl}$ ( $\mathrm{pH} \mathrm{7.0)}$ ), and $1 \mathrm{mM} \mathrm{Na}{ }_{2}$ EDTA containing $0\left(0 \mathrm{~mol} \mathrm{~L}^{-1}\right), 10\left(0.5 \mathrm{~mol} \mathrm{~L}^{-1}\right), 20\left(1 \mathrm{~mol} \mathrm{~L}^{-1}\right), 30$ $\left(1.5 \mathrm{~mol} \mathrm{~L}^{-1}\right)$, or $40\left(2 \mathrm{~mol} \mathrm{~L}^{-1}\right) \mathrm{wt} \%$ PEG200 at $37^{\circ} \mathrm{C}$.

AP-9, and AP-10 possessing abasic sites in the bottom Gquartet plane $\left(2.4 \mathrm{kcal} \mathrm{mol}^{-1}\right)$. These results show that the position of the abasic site significantly affects the abasic site effect on the thermodynamics of G-quadruplex. Interestingly, this order was the same as that observed for the values of $\Delta \Delta G_{37(\mathrm{MC})}^{\circ}$, that is, the molecular crowding effect on the stabilizing of the G-quadruplexes with abasic sites at different positions. Moreover, a comparison of the values of $\Delta H^{\circ}$ and $T \Delta S^{\circ}$ of $\mathrm{AP}-1 \sim \mathrm{AP}-11$ shows that the destabilization of G-quadruplexes by the abasic sites was due to unfavourable enthalpy changes. In addition, the values of $\Delta H^{\circ}$ also depended on the position of the abasic site. Thus, it is possible that the enthalpy change of G-quadruplexes depending on the position of the abasic site is related to the molecular crowding effects on the thermodynamics of Gquadruplexes.

3.5. The Relationship between Molecular Crowding and Abasic Site Effects on the Thermodynamics of G-Quadruplexes. We found that stabilization of G-quadruplexes by molecular crowding and destabilization of G-quadruplexes by abasic sites were due to favourable and unfavourable enthalpy changes, respectively. In order to understand a possible mechanism for molecular crowding effects that depend on the position of the abasic site, we compared molecular crowding and abasic site effects on enthalpy changes for G-quadruplex formation. Figure 5 shows the molecular crowding effects on the enthalpy change for the formation of G-quadruplexes containing abasic sites $\left\{\Delta H_{(40 \mathrm{wt} \% \text { PEG200) }}^{\circ}-\right.$ $\left.\Delta H_{(0 \text { wt } \% \text { PEG200) }}^{\circ}\right\}$ versus the abasic site effects on enthalpy changes for $\mathrm{G}$-quadruplex formation under dilute conditions

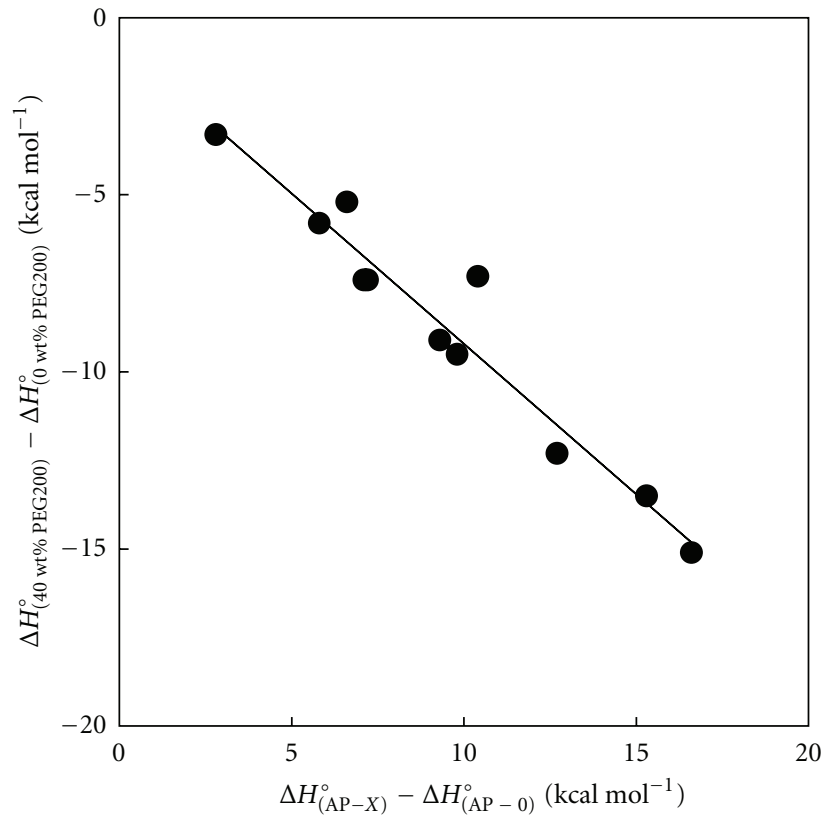

Figure 5: Plots of the molecular crowding effects on enthalpy change for G-quadruplex formation $\Delta H_{(40 \mathrm{wt} \% \text { PEG200) - }}^{\circ}$ $\Delta H_{(0 \mathrm{wt} \% \text { PEG200) }}^{\circ}$ versus abasic site effects on enthalpy change for G-quadruplex formation $\Delta H_{(\mathrm{AP}-X)}^{\circ}-\Delta H_{(\mathrm{AP}-0)}^{\circ}$ at $0 \mathrm{wt} \%$ PEG200 ( $X$ indicates the numbers from 1 to 11 ) in a buffer of $100 \mathrm{mM}$ $\mathrm{NaCl}, 50 \mathrm{mM}$ Tris- $\mathrm{HCl}$ ( $\mathrm{pH} 7.0$ ), and $1 \mathrm{mM} \mathrm{Na}{ }_{2}$ EDTA at $0 \mathrm{wt} \%$ $\left(0 \mathrm{~mol} \mathrm{~L}^{-1}\right)$ and $40 \mathrm{wt} \%\left(2 \mathrm{~mol} \mathrm{~L}^{-1}\right)$ PEG200.

$\Delta H_{(\mathrm{AP}-\mathrm{X})}^{\circ}-\Delta H_{(\mathrm{AP}-0)}^{\circ}$, where $X$ indicates numbers from 1 to 11. The plot reveals that the molecular crowding effects on the enthalpy change for the formation of G-quadruplexes containing abasic sites at different positions decreased linearly as the abasic site effects on enthalpy change increased. The negative slope shows that a G-quadruplex having a more unfavourable enthalpic change induced by an abasic site is more enthalpically stabilized by molecular crowding. Interestingly, the slope was around -1 . This compensation relationship between the enthalpy changes suggests that molecular crowding can restore an unfavourable enthalpic loss induced by an abasic site, which may be useful to maintain a G-quadruplex structure with an abasic site under molecular crowding conditions.

Olsen et al. reported that base substitution in the loops causes a decrease in the thermal stability of the G-quadruplex, which can be explained in terms of stacked loops on the G-quartets and base-base stacking within the loops, as well as their overall hydration contributions [15]. Moreover, in case of a DNA duplex with an abasic site, destabilization depends on neighbouring bases due to the different stacking conformations and energies between the substituted base and neighbouring bases [47-49]. Thus, it is possible that the molecular crowding effects on the thermodynamics of G-quadruplexes including a single abasic site depended on position of the abasic site due to local stacking energies altered. However, further studies are required of base substitution in the loop region of G-quadruplexes under 
different topologies. In contrast to duplexes, the effect of an abasic site on the thermodynamics of G-quadruplexes largely depends on the stacking position. This dependency can create a polymorphic nature in the structure and thermal stability of G-quadruplexes, which should affect biological systems related to guanine-rich DNA sequences. However, quantitative results obtained here imply that molecular crowding can reduce such risks. This buffering effect to reduce responses of biomolecules against extended stimuli has been proposed as one of the important functions of molecular crowding to maintain homeostasis of cells [50].

\section{Conclusion}

We examined the effects of molecular crowding on the structure and stability of G-quadruplexes with abasic sites at different positions. The CD spectra showed that molecular crowding did not affect the topology of G-quadruplexes. On the other hand, UV melting analysis showed that the effects of molecular crowding on the thermodynamic stability of G-quadruplexes depended on the position of the abasic site. Moreover, a systematic comparison of the effects of molecular crowding and abasic sites on the thermodynamic parameters demonstrated that the molecular crowding effects on enthalpy changes during the formation of G-quadruplexes with abasic sites at different positions decreased linearly as the abasic site effects increased. This compensatory relationship suggests that molecular crowding plays a role in the maintenance of G-quadruplex structures with abasic sites in cells.

\section{Acknowledgment}

This work was supported in part by Grants-in-Aid for Scientific Research and the "Core Research" project (20092014), from the Ministry of Education, Culture, Sports, Science and Technology, Japan, the Hirao Taro Foundation of the Konan University Association for Academic Research, and the Long-Range Research Initiative Project of Japan Chemical Industry Association.

\section{References}

[1] S. B. Zimmerman and A. P. Minton, "Macromolecular crowding: biochemical, biophysical, and physiological consequences," Annual Review of Biophysics and Biomolecular Structure, vol. 22, pp. 27-65, 1993.

[2] A. P. Minton, "The influence of macromolecular crowding and macromolecular confinement on biochemical reactions in physiological media," Journal of Biological Chemistry, vol. 276, no. 14, pp. 10577-10580, 2001.

[3] R. J. Ellis and A. P. Minton, "Cell biology: join the crowd," Nature, vol. 425, no. 6953, pp. 27-28, 2003.

[4] O. Medalia, I. Weber, A. S. Frangakis, D. Nicastro, G. Gerisch, and W. Baumeister, "Macromolecular architecture in eukaryotic cells visualized by cryoelectron tomography," Science, vol. 298, no. 5596, pp. 1209-1213, 2002.

[5] R. J. Ellis, "Macromolecular crowding: an important but neglected aspect of the intracellular environment," Current Opinion in Structural Biology, vol. 11, no. 1, pp. 114-119, 2001.
[6] P. R. Davis-Searles, A. J. Saunders, D. A. Erie, D. J. Winzor, and G. J. Pielak, "Interpreting the effects of small uncharged solutes on protein-folding equilibria," Annual Review of Biophysics and Biomolecular Structure, vol. 30, pp. 271-306, 2001.

[7] J. R. Wenner and V. A. Bloomfield, "Crowding effects on EcoRV kinetics and binding," Biophysical Journal, vol. 77, no. 6, pp. 3234-3241, 1999.

[8] Y. Sasaki, D. Miyoshi, and N. Sugimoto, "Regulation of DNA nucleases by molecular crowding," Nucleic Acids Research, vol. 35, no. 12, pp. 4086-4093, 2007.

[9] C. H. Spink and J. B. Chaires, "Selective stabilization of triplex DNA by poly(ethylene glycols)," Journal of the American Chemical Society, vol. 117, no. 51, pp. 12887-12888, 1995.

[10] R. Goobes and A. Minsky, "Thermodynamic aspects of triplex DNA formation in crowded environments," Journal of the American Chemical Society, vol. 123, no. 50, pp. 12692-12693, 2001.

[11] S. Nakano, H. Karimata, T. Ohmichi, J. Kawakami, and N. Sugimoto, "The effect of molecular crowding with nucleotide length and cosolute structure on DNA duplex stability," Journal of the American Chemical Society, vol. 126, no. 44, pp. 14330-14331, 2004.

[12] D. Miyoshi, H. Karimata, and N. Sugimoto, "Hydration regulates thermodynamics of G-quadruplex formation under molecular crowding conditions," Journal of the American Chemical Society, vol. 128, no. 24, pp. 7957-7963, 2006.

[13] D. Miyoshi, K. Nakamura, H. Tateishi-Karimata, T. Ohmichi, and N. Sugimoto, "Hydration of watson crick base pairs and dehydration of hoogsteen base pairs inducing structural polymorphism under molecular crowding conditions," Journal of the American Chemical Society, vol. 131, no. 10, pp. 3522-3531, 2009.

[14] M. C. Miller, R. Buscaglia, J. B. Chaires, A. N. Lane, and J. O. Trent, "Hydration is a major determinant of the G-quadruplex stability and conformation of the human telomere $3^{\prime}$ sequence of $\mathrm{d}\left(\mathrm{AG}_{3}\left(\mathrm{TTAG}_{3}\right)_{3}\right)$," Journal of the American Chemical Society, vol. 132, no. 48, pp. 17105-17107, 2010.

[15] C. M. Olsen, H. T. Lee, and L. A. Marky, "Unfolding thermodynamics of intramolecular G-quadruplexes: base sequence contributions of the loops," Journal of Physical Chemistry B, vol. 113, no. 9, pp. 2587-2595, 2009.

[16] A. Arora and S. Maiti, "Stability and molecular recognition of quadruplexes with different loop length in the absence and presence of molecular crowding agents," Journal of Physical Chemistry B, vol. 113, no. 25, pp. 8784-8792, 2009.

[17] A. Rajendran, S. Nakano, and N. Sugimoto, "Molecular crowding of the cosolutes induces an intramolecular i-motif structure of triplet repeat DNA oligomers at neutral $\mathrm{pH}$," Chemical Communications, vol. 46, no. 8, pp. 1299-1301, 2010.

[18] S. Nakano, H. T. Karimata, Y. Kitagawa, and N. Sugimoto, "Facilitation of RNA enzyme activity in the molecular crowding media of cosolutes," Journal of the American Chemical Society, vol. 131, no. 46, pp. 16881-16888, 2009.

[19] A. K. Todd, M. Johnston, and S. Neidle, "Highly prevalent putative quadruplex sequence motifs in human DNA," Nucleic Acids Research, vol. 33, no. 9, pp. 2901-2907, 2005.

[20] R. C. Allsopp, H. Vaziri, C. Patterson et al., "Telomere length predicts replicative capacity of human fibroblasts," Proceedings of the National Academy of Sciences of the United States of America, vol. 89, no. 21, pp. 10114-10118, 1992.

[21] L. A. Klobutcher, M. T. Swanton, P. Donini, and D. M. Prescott, "All gene-sized DNA molecules in four species of hypotrichs have the same terminal sequence and an unusual $3^{\prime}$ terminus," Proceedings of the National Academy of Sciences of 
the United States of America, vol. 78, no. 5, pp. 3015-3019, 1981.

[22] J. R. Williamson, "G-quartet structures in telomeric DNA," Annual Review of Biophysics and Biomolecular Structure, vol. 23, pp. 703-730, 1994.

[23] J. L. Huppert and S. Balasubramanian, "Prevalence of quadruplexes in the human genome," Nucleic Acids Research, vol. 33, no. 9, pp. 2908-2916, 2005.

[24] E. H. Blackburn and P. B. Challoner, "Identification of a telomeric DNA sequence in Trypanosoma brucei," Cell, vol. 36, no. 2, pp. 447-457, 1984.

[25] E. H. Blackburn, "Structure and function of telomeres," Nature, vol. 350, no. 6319, pp. 569-573, 1991.

[26] D. J. Patel, A. T. Phan, and V. Kuryavyi, "Human telomere, oncogenic promoter and 5'-UTR G-quadruplexes: diverse higher order DNA and RNA targets for cancer therapeutics," Nucleic Acids Research, vol. 35, no. 22, pp. 7429-7455, 2007.

[27] A. C. Vallur and N. Maizels, "Activities of human exonuclease 1 that promote cleavage of transcribed immunoglobulin switch regions," Proceedings of the National Academy of Sciences of the United States of America, vol. 105, no. 43, pp. 16508-16512, 2008.

[28] J. W. Szostak and E. H. Blackburn, "Cloning yeast telomeres on linear plasmid vectors,” Cell, vol. 29, no. 1, pp. 245-255, 1982.

[29] C. W. Greider and E. H. Blackburn, "The telomere terminal transferase of tetrahymena is a ribonucleoprotein enzyme with two kinds of primer specificity," Cell, vol. 51, no. 6, pp. 887898, 1987.

[30] E. S. Baker, J. T. Lee, J. L. Sessler, and M. T. Bowers, "Cyclo[n]pyrroles: size and site-specific binding to G-quadruplexes," Journal of the American Chemical Society, vol. 128, no. 8, pp. 2641-2648, 2006.

[31] J. Seenisamy, S. Bashyam, V. Gokhale et al., "Design and synthesis of an expanded porphyrin that has selectivity for the c-MYC G-quadruplex structure," Journal of the American Chemical Society, vol. 127, no. 9, pp. 2944-2959, 2005.

[32] P. S. Shirude, E. R. Gillies, S. Ladame et al., "Macrocyclic and helical oligoamides as a new class of G-quadruplex ligands," Journal of the American Chemical Society, vol. 129, no. 39, pp. 11890-11891, 2007.

[33] H. Yaku, T. Murashima, D. Miyoshi, and N. Sugimoto, "Anionic phthalocyanines targeting G-quadruplexes and inhibiting telomerase activity in the presence of excessive DNA duplexes," Chemical Communications, vol. 46, no. 31, pp. 5740-5742, 2010.

[34] B. van Steensel, A. Smogorzewska, and T. De Lange, "TRF2 protects human telomeres from end-to-end fusions," Cell, vol. 92, no. 3, pp. 401-413, 1998.

[35] T. Lindahl, "Instability and decay of the primary structure of DNA," Nature, vol. 362, no. 6422, pp. 709-715, 1993.

[36] T. Lindahl and B. Nyberg, "Rate of depurination of native deoxyribonucleic acid," Biochemistry, vol. 11, no. 19, pp. 3610 3618, 1972.

[37] J. Tchou, H. Kasai, S. Shibutani et al., "8-oxoguanine (8-hydroxyguanine) DNA glycosylase and its substrate specificity," Proceedings of the National Academy of Sciences of the United States of America, vol. 88, no. 11, pp. 4690-4694, 1991.

[38] V. Esposito, L. Martino, G. Citarella et al., "Effects of abasic sites on structural, thermodynamic and kinetic properties of quadruplex structures," Nucleic Acids Research, vol. 38, no. 6, pp. 2069-2080, 2009.
[39] P. Školáková, K. Bednářová, M. Vorlíčková, and J. Sagi, “Quadruplexes of human telomere $\mathrm{dG}_{3}\left(\mathrm{TTAG}_{3}\right)_{3}$ sequences containing guanine abasic sites," Biochemical and Biophysical Research Communications, vol. 399, no. 2, pp. 203-208, 2010.

[40] N. Sugimoto, S. Nakano, M. Katoh et al., "Thermodynamic parameters to predict stability of RNA/DNA hybrid duplexes," Biochemistry, vol. 34, no. 35, pp. 11211-11216, 1995.

[41] S. Nakano, T. Kanzaki, and N. Sugimoto, "Influences of Ribonucleotide on a duplex conformation and its thermal stability: study with the chimeric RNA-DNA strands," Journal of the American Chemical Society, vol. 126, no. 4, pp. 1088-1095, 2004.

[42] J. L. Mergny, J. Li, L. Lacroix, S. Amrane, and J. B. Chaires, "Thermal difference spectra: a specific signature for nucleic acid structures," Nucleic Acids Research, vol. 33, no. 16, p. e138, 2005.

[43] Y. Wang and D. J. Patel, "Solution structure of the human telomeric repeat d $\left[\mathrm{AG}_{3}\left(\mathrm{~T}_{2} \mathrm{AG}_{3}\right)_{3}\right]$ G-tetraplex," Structure, vol. 1, no. 4, pp. 263-282, 1993.

[44] N. Sugimoto, M. Nakano, and S. Nakano, "Thermodynamics - structure relationship of single mismatches in RNA/DNA duplexes," Biochemistry, vol. 39, no. 37, pp. 11270-11281, 2000.

[45] V. V. Vasilevskaya, A. R. Khokhlov, Y. Matsuzawa, and K. Yoshikawa, "Collapse of single DNA molecule in poly(ethylene glycol) solutions," The Journal of Chemical Physics, vol. 102, no. 16, pp. 6595-6602, 1995.

[46] Z. Chen, K. W. Zheng, Y. H. Hao, and Z. Tan, "Reduced or diminished stabilization of the telomere G-quadruplex and inhibition of telomerase by small chemical ligands under molecular crowding condition," Journal of the American Chemical Society, vol. 131, no. 30, pp. 10430-10438, 2009.

[47] J. Sági, B. Hang, and B. Singer, "Sequence-dependent repair of synthetic AP sites in 15-mer and 35-mer oligonucleotides: role of thermodynamic stability imposed by neighbor bases," Chemical Research in Toxicology, vol. 12, no. 10, pp. 917-923, 1999.

[48] J. Sági, A. B. Guliaev, and B. Singer, "15-Mer DNA duplexes containing an abasic site are thermodynamically more stable with adjacent purines than with pyrimidines," Biochemistry, vol. 40, no. 13, pp. 3859-3868, 2001.

[49] C. A. Gelfand, G. E. Plum, A. P. Grollman, F. Johnson, and K. J. Breslauer, "Thermodynamic consequences of an abasic lesion in duplex DNA are strongly dependent on base sequence," Biochemistry, vol. 37, no. 20, pp. 7321-7327, 1998.

[50] R. Goobes, N. Kahana, O. Cohen, and A. Minsky, "Metabolic buffering exerted by macromolecular crowding on DNADNA interactions: origin and physiological significance," Biochemistry, vol. 42, no. 8, pp. 2431-2440, 2003. 

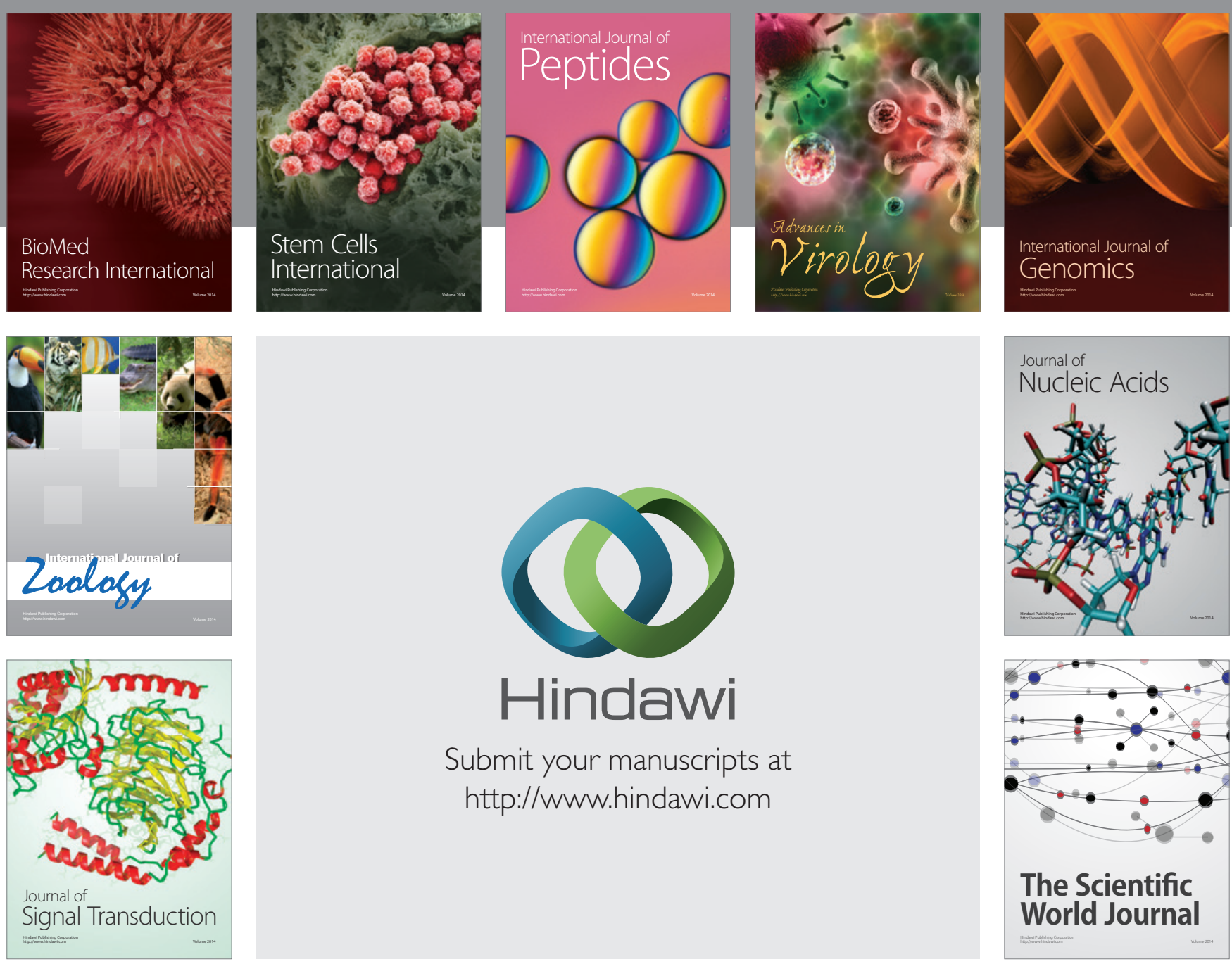

Submit your manuscripts at

http://www.hindawi.com
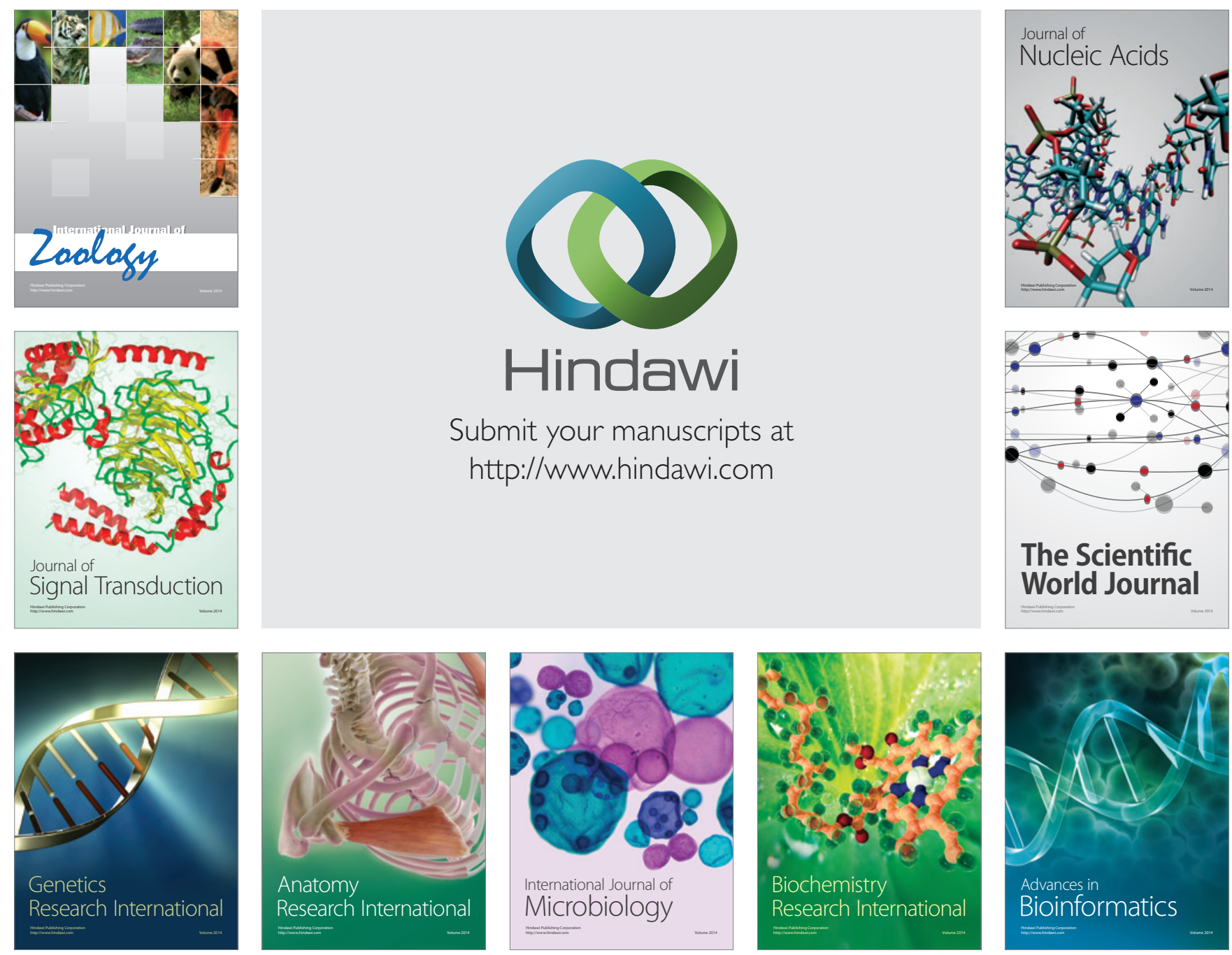

The Scientific World Journal
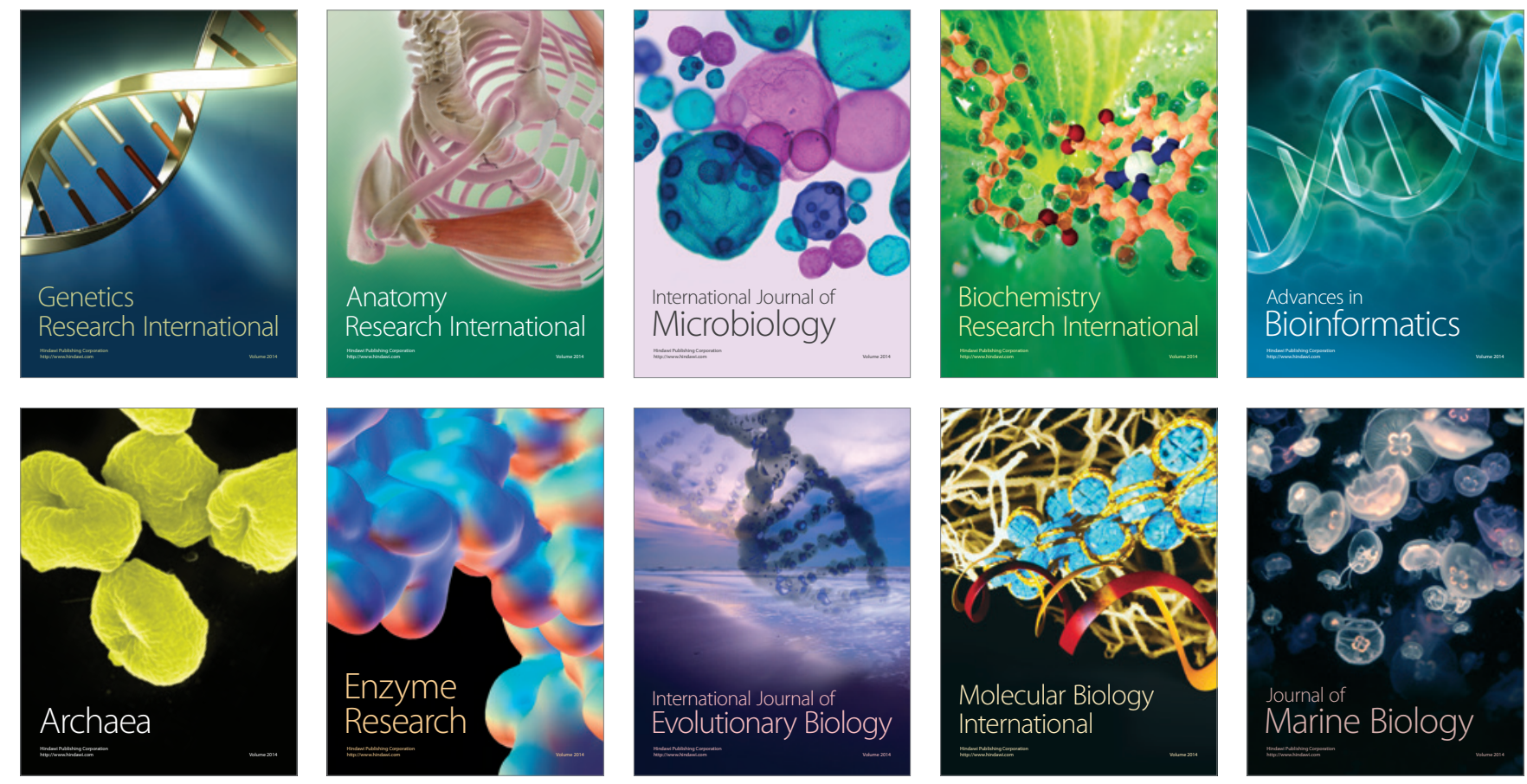